\title{
The cost-effectiveness of unilateral cochlear implants in UK adults
}

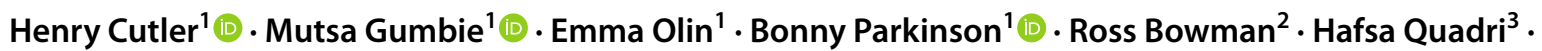 \\ Timothy Mann ${ }^{3}$
}

Received: 8 April 2020 / Accepted: 21 October 2021 / Published online: 2 November 2021

(c) The Author(s) 2021

\begin{abstract}
Objective The National Institute for Health and Care Excellence (NICE) updated its eligibility criteria for unilateral cochlear implants (UCIs) in 2019. NICE claimed this would not impact the cost-effectiveness results used within its 2009 technology appraisal guidance. This claim is uncertain given changed clinical practice and increased healthcare unit costs. Our objective was to estimate the cost-effectiveness estimates of UCIs in UK adults with severe to profound hearing loss within the contemporary NHS environment.

Methods A cost-utility analysis employing a Markov model was undertaken to compare UCIs with hearing aids or no hearing aids for people with severe to profound hearing loss. A clinical pathway was developed to estimate resource use. Health-related quality of life, potential adverse events, device upgrades and device failure were captured. Unit costs were derived mostly from the NHS data. Probabilistic sensitivity analysis further assessed the effect of uncertain model inputs.

Results A UCI is likely to be deemed cost-effective when compared to a hearing aid ( $£ 11,946 /$ QALY) or no hearing aid (£10,499/QALY). A UCI has an $93.0 \%$ and $98.7 \%$ likelihood of being cost-effective within the UK adult population when compared to a hearing aid or no hearing aid, respectively. ICERs were mostly sensitive to the proportion of people eligible for cochlear implant, discount rate, surgery and device costs and processor upgrade cost.

Conclusion UCIs remain cost-effective despite changes to clinical practice and increased healthcare unit costs. Updating the NICE criteria to provide better access UCIs is projected to increase annual implants in adults and children by $70 \%$ and expenditure by $£ 28.6$ million within three years. This increased access to UCIs will further improve quality of life of recipients and overall social welfare.
\end{abstract}

Keywords Cost-utility $\cdot$ Cochlear implant $\cdot$ Hearing aid $\cdot$ Hearing loss $\cdot$ Economic evaluation

JEL Classification D61 $\cdot$ I18 $\cdot$ I19

\section{Introduction}

Around 11 million people in the UK live with permanent hearing loss, most of which results from age related damage to the cochlear due to environment and genetic factors [1]. A unilateral cochlear implant (UCI) can improve hearing in people with severe to profound sensorineural hearing loss. Speech recognition is better with cochlear implants

Henry Cutler

Henry.cutler@mq.edu.au

1 Macquarie University Centre for the Health Economy, Sydney, Australia

2 Health Technology Analysts, Sydney, Australia

3 Cochlear Limited, Sydney, Australia compared to hearing aids for adults with post-lingual severe to profound bilateral hearing loss, regardless of age [2-8]. While pre-lingual deafened people derive significant benefits from cochlear implants, people with post-lingual severe to profound hearing loss receive the greatest improvements in speech perception $[8,9]$. Gains in speech perception scores are greatest in the first few months, but performance continues to improve over time [10,11].

Improved hearing from using a UCI also improves quality of life. People have reported improvements in the Geriatric Depression Scale [12, 13], improved mental health and social functioning in the Short Form Health Survey (SF-36) $[10,14-16]$, improved health-related quality of life as measured by the Health Utilities Index Mark 3 (HUI3) [11], and 
improved general wellbeing, as measured by the Glasgow Benefit Inventory [17, 18].

Many people in the UK with severe to profound sensorineural hearing loss have missed out on receiving a UCI despite their potential benefits. One study concluded five\% of adults eligible for a cochlear implant had received one within the UK, arguing that low provision and utilisation resulted from limited audiological awareness and screening programs [19]. Another study argued that NICE guidance was too restrictive compared to other countries [20]. Research also suggested that the Bamford-Kowal-Bench (BKB) sentence test was not appropriate for assessing the potential benefits from a cochlear implant for some users, particularly pre-lingual deaf adults, people without English as their native language, and those with low-frequency residual hearing [21].

Previous National Institute for Health and Care Excellence (NICE) guidance stated that an adult must have severe to profound hearing loss (threshold greater than $90 \mathrm{~dB} \mathrm{HL}$ at 2 or more frequencies $(500,1000,2000$ and $4000 \mathrm{~Hz}$ ) and not receive adequate benefit from acoustic hearing aids for a cochlear implant to be funded by the National Health Service (NHS). NICE defined adequate benefit from acoustic hearing aids in adults as a score of $50 \%$ or greater using BKB sentence testing at a sound intensity of $70 \mathrm{~dB}$ SPL [22].

NICE updated its guidance in March 2019 [23]. Severe to profound hearing loss became defined using a threshold of equal to or greater than $80 \mathrm{~dB} H \mathrm{HL}$ at 2 or more frequencies $(500,1000,2000$ and $4000 \mathrm{~Hz})$ bilaterally without acoustic hearing aids. Adequate benefit from acoustic hearing aids also became defined for adults as a phoneme score of $50 \%$ or greater on the Arthur Boothroyd (AB) word test presented at $70 \mathrm{dBA}$.

Updated eligibility criteria are projected to increase annual access to UCIs by around $70 \%$ and cost around $£ 28.6$ million annually within three years [24]. While studies that have evaluated the cost-effectiveness of cochlear implants in the UK have generally found UCIs are costeffective [5, 30-33], the cost-effectiveness of UCIs has not been explored since 2009, when a NICE Health Technology Assessment Report was produced [25], and relied upon to develop the original guidance. That study primarily relied on estimated costs that could be considered an unreliable representation of costs within clinical settings today. Costs were estimated from a study of five hospitals in the NHS between 1992 and99, which apportioned administration costs across planned patient contact hours sourced from clinicians to estimate resource unit costs per hour of contact, and then projected costs using a declining exponential function [5]. It also used costs derived from consultation with clinicians and hospital accountants for imaging, surgical sessions, radiography, cochlear implant system and repairs, and a hospital stay [5] These costs were converted from euros to pounds and inflated to 2005-2006 prices [25].

The cost-effectiveness of UCIs in the UK adult population has not been investigated since. NICE noted that changes to the eligibility criteria within its 2019 technology appraisal guidance update would not impact the cost-effectiveness results presented within the NICE Health Technology Assessment Report. It reasoned that the original costeffectiveness estimates included the additional population defined under the new eligibility criteria and that device costs had since declined [26].

This claim is uncertain given changes in the NHS environment since the NICE Health Technology Assessment Report was completed. While device costs have recently decreased, they represent only around $39 \%$ of the total cost associated with a UCI [25], with the remaining proportion associated with assessment, surgical implantation, activation and tuning, rehabilitation and maintenance. Continual increases in the Hospital and Community Health Services (HCHS) index suggest unit costs within the NHS have increased by $37 \%$ between 2005-06 and 2019-2020 [27, 28]. Increased unit costs may have increased the incremental cost-effectiveness ratio (ICER) beyond the NICE cost-effectiveness threshold. If this has occurred, extending access to UCIs will improve health outcomes for recipients, but will reduce social welfare given the additional resource could be spent elsewhere in the NHS with potentially greater returns [29].

Our study aims to evaluate the cost-effectiveness of UCIs compared to hearing aids and no hearing aids in UK adults with severe to profound hearing loss within a contemporary NHS environment. Our target population includes adults who had previously received benefits from a hearing aid and adults who had not. Our study represents the first alternative cost-effectiveness estimate of UCIs compared to that presented within the NICE Health Technology Assessment Report in 2009. It is timely given new guidance is expected to significantly increase access to UCIs for UK adults with severe to profound hearing loss.

We update previous results from the NICE Health Technology Assessment Report in three important ways. First, we use a contemporary UCI clinical pathway for the UK developed in consultation with clinicians. Our pathway therefore inherently captures change in UCI clinical pathways over the last two decades. While we do not quantify this change directly, there is evidence that the clinical pathway has changed that could significantly impact costs. For example, costs within the NICE Health Technology Assessment Report relied on clinical estimates of time spent in hospital after cochlear implant surgery, which was estimated to be $72 \mathrm{~h}$ [5]. Today most adults receive a UCI in an outpatient setting within the UK, or spend one night in hospital for observation. 
Second, our study differs from the NICE Health Technology Assessment Report by relying on current NHS reported costs and tariffs derived from the NHS National Schedule of Reference Costs [30]. This presents national average costs across all NHS providers, and therefore capture all hospitals providing UCIs. It also accounts for changes in the price of UCIs, which are expected to have occurred considering UCI devices have been miniaturised and undergone significant technological change to processors and electrodes since the mid 1990s [31]. Third, our study accounts for changes in short- and long-term adverse events associated with UCIs that has occurred through improvements in surgery process and improved cochlear implant devices. We rely on more recent clinical studies that have evaluated adverse events from cochlear implant surgery and UCIs.

\section{Methods}

A UCI is expected to improve hearing ability over the remaining life of a recipient. There are also ongoing lifetime costs, such as sound processor upgrades, consumables (cables and batteries), audiologist consultations for maintenance and upgrades, and costs to explant and reimplant a cochlear implant if the device fails or due to medical reasons.

A Markov model was employed to capture the chronic nature of severe to profound hearing loss in adults, treatment pathways and health outcomes associated with UCIs and hearing aids. It allowed for death from other causes (which increases in likelihood as the cohort ages) to be incorporated.

Parameter estimates were incorporated as mean values with an associated prior distribution representing uncertainty surrounding the mean. Distributions were sourced from the literature, along with expert opinion where data on distributions were not available. Assumptions on distributions were made for those remaining parameter estimates, based on the family to which the parameter belonged.

The model took an NHS perspective and a lifetime horizon to capture all differences in lifetime benefits and costs associated with a UCI. The discount rate for future health outcomes and costs was $3.5 \%$, with a $1.5 \%$ discount rate tested within a sensitivity analysis. Both these discount rates are recommended by NICE guidelines within their Technology Appraisal Programme [32]. A discount rate of 3\% and $5 \%$ was also tested within the sensitivity analysis to help compare results between countries, as recommended by The Panel on Cost-effectiveness in Health and Medicine [33]. The model employed a six-month cycle length. All costs were expressed in 2018 UK pound prices.

\section{Model structure}

The model explored alternative combinations of interventions and comparators, resulting in several economic evaluation scenarios. These included a UCI versus a hearing aid and a UCI versus no hearing aid. The model incorporated several health states to capture the treatment pathway and potential adverse events and device failures and death from other causes (Fig. 1).

Individuals can remain in their initial state ('UCI'), or experience an adverse event. These were categorised as either short-term adverse events that lasted one cycle (i.e., six months), or long-term events that lasted for their remaining lifetime (Fig. 2).

Internal and external device failure or external device upgrade can either be immediate (in the first cycle) following surgery, or it can occur over time. This was incorporated into the model using a time-dependent probability calculated from cumulative survival values.

Individuals who experience an internal device failure may choose to re-operate and replace the device (Fig. 3). These individuals may experience an adverse event, which could either be short term or long term. Individuals who experience an internal device failure may also choose to re-operate and remove the device, thereby ceasing to use cochlear implants. Alternatively, they could undertake no operation and remain with a faulty device and cease to use the cochlear implant.

Individuals who experience an external device failure may choose to replace the device or remain with a faulty device and cease to use the cochlear implant. There is no risk of death or adverse events with external device failure. Individuals who experience an external device upgrade will have the device replaced. There is no risk of death or adverse events with external device upgrade.

Patients who cease to use a cochlear implant can either use a hearing aid, where they can be compliant or non-compliant, or they can choose not to use a hearing aid. 'Death from surgery or natural causes' is an absorbing health state, accounting for the risk associated with cochlear implant surgery and general all-cause mortality over time in the UK adult population.

\section{Model assumptions}

Several structural assumptions were required within the Markov model. Persons were assumed to have been diagnosed with severe to profound sensorineural hearing loss in both ears. All persons deemed eligible for a cochlear implant were assumed to receive a cochlear implant (i.e., no persons drop off the waiting list before surgery). Any future hearing loss the patient experiences does not impact health outcomes given hearing loss is already severe to profound. 


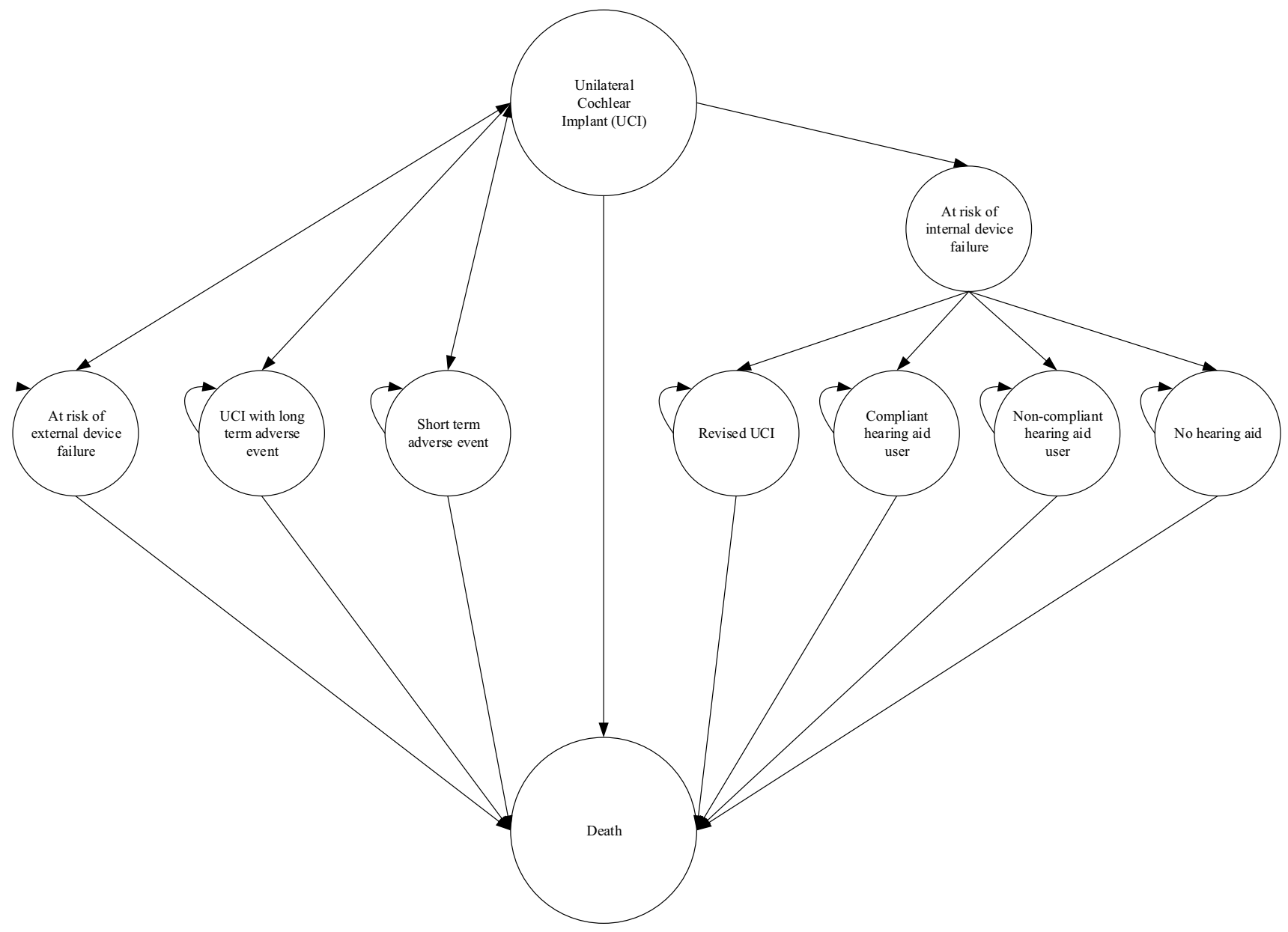

Fig. 1 Markov model structure for unilateral cochlear implants

Fig. 2 Treatment pathway for adults with severe to profound sensorineural hearing loss

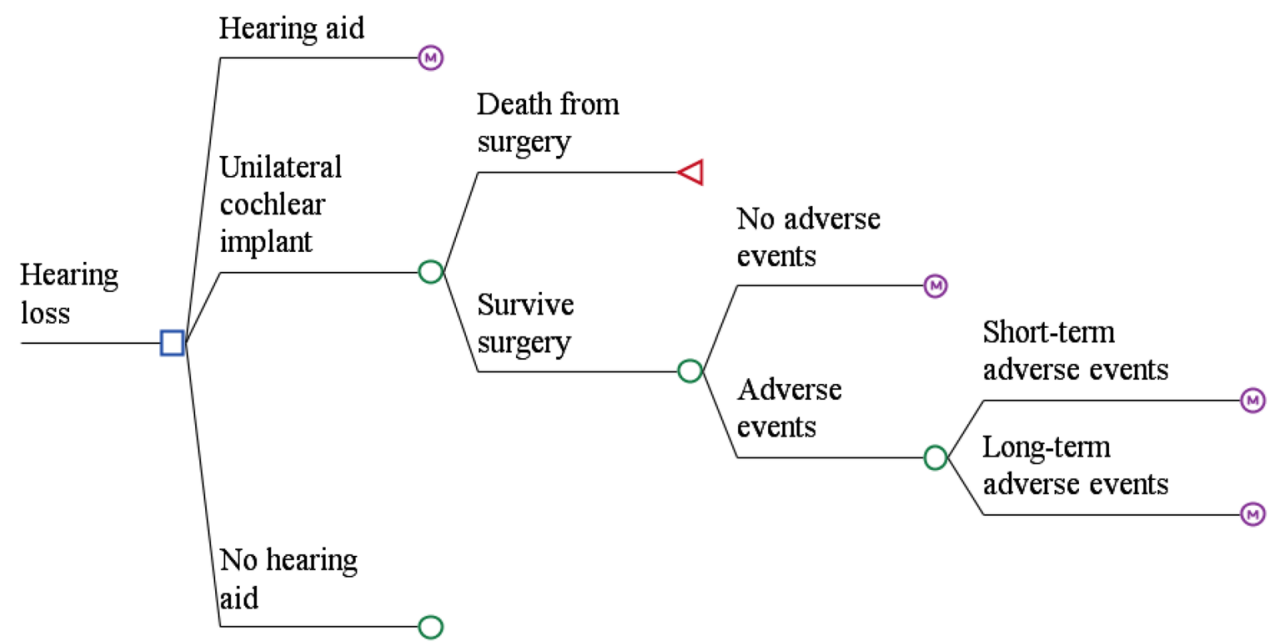




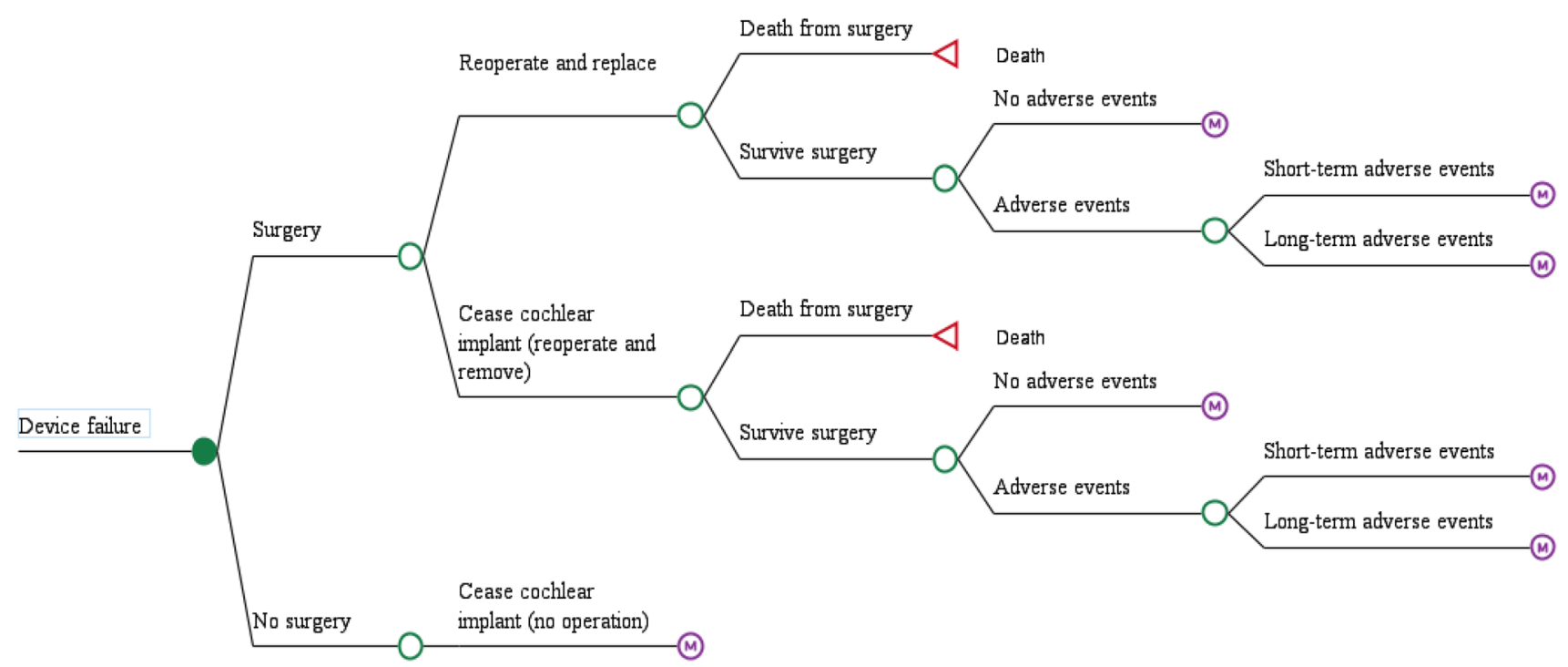

Fig. 3 Treatment pathway for patients experiencing and internal device failure

Those persons using a hearing aid (instead of a UCI) were either compliant users or non-complaint users.

Several assumptions were made regarding the device itself. Annual equipment maintenance costs start in the second year from receiving a cochlear implant. The internal component of a cochlear implant lasts a lifetime, unless trauma occurs resulting in device failure, and that all cochlear implants are $3 \mathrm{~T}$ MRI compatible. ${ }^{1}$ Cochlear implant software upgrade does not provide additional health utility benefits, nor does a cochlear implant impact the prevalence or severity of other health conditions (e.g., depression or dementia). Both these assumptions are likely to be conservative as upgrades could improve hearing and research has linked improved hearing from cochlear implants to improved cognitive function [12]; however, no studies have quantified the impact on utilities. It was also assumed that cochlear implant surgery is never abandoned during the procedure, nor results in death, all initial cochlear implants and re-implants are successful, and that a cochlear implant does not impact life expectancy.

\section{Model inputs}

The Markov model required several underlying parameters related to its structure, device failure, probability of re-implantation, and implant type, among other categories (Table 1). Data were initially identified through a NICE Health Technology Assessment Report on the

\footnotetext{
${ }^{1}$ Many cochlear implants currently in use are not $3 \mathrm{~T}$ compatible. We made this assumption because nearly all new cochlear implants will be $3 \mathrm{~T}$ compatible soon.
}

cost-effectiveness of cochlear implants in the UK; [25] a health technology assessment report produced by Health Quality Ontario on the cost-effectiveness of cochlear implants in Canada; [34] and an unpublished systematic literature review report on the clinical effectiveness of cochlear implants undertaken by Oxford PharmaGenesis Ltd.

Literature reviews on transition probabilities and utilities associated with hearing aids and cochlear implants were also conducted up to October 2018 to update and supplement data presented in the three primary sources. Search terms used within the NICE Health Technology Assessment Report were reviewed for their appropriateness, and applied to Ovid Medline and Embase. New search terms were developed for the literature review on utilities. No meta-analyses on utilities were performed due to a high degree of clinical heterogeneity in addition to poor reporting of methods in studies of cochlear implants. Expert opinion was used to fill data gaps associated with resource use and costs.

\section{Resource use}

Resource use was derived from published literature, grey literature and expert opinion. This information was used to develop a treatment pathway that an average patient is expected to take, from receiving an initial referral to a cochlear implant program from an audiologist, to receiving and using a cochlear implant (Fig. 4). Resource use was divided into pre-implant assessment, surgery (the implant device and surgery), device programming and maintenance, sound processor replacement/upgrade, explants and re-implants, and complications (short- and long-term adverse events). 
Table 1 Model parameters

\begin{tabular}{|c|c|c|c|c|}
\hline Parameter & Value & Source & Confidence interval & Distribution \\
\hline Time horizon & Lifetime & $\begin{array}{l}\text { Authors assumption based on the expected } \\
\text { benefits and costs of a cochlear implant }\end{array}$ & NA & NA \\
\hline Annual discount rate & $3.5 \%$ & $\begin{array}{l}\text { NICE guidelines (Technology Appraisal } \\
\text { Programme) }\end{array}$ & $1.5 \%, 5.0 \%$ & NA \\
\hline Average age & 52.8 years & $\begin{array}{l}\text { Cochlear Limited, based on a distribution } \\
\text { of age } 18 \text { years and over upon receipt of a } \\
\text { cochlear implant in the UK }\end{array}$ & NA & NA \\
\hline $\begin{array}{l}\text { Proportion of people deemed eligible for a } \\
\text { cochlear implant after initial assessment }\end{array}$ & 0.70 & Expert opinion & $0.372,0.938$ & Beta \\
\hline $\begin{array}{l}\text { Probability of a cochlear implant internal } \\
\text { failure }^{\mathrm{a}}\end{array}$ & 0.025 & Wang et al. [53] & $0.011,0.040$ & Beta \\
\hline $\begin{array}{l}\text { Probability of a cochlear implant external } \\
\text { failure }^{\mathrm{a}}\end{array}$ & 0.004 & Wang et al. [53] & $0.002,0.018$ & Beta \\
\hline $\begin{array}{l}\text { Probability a patient elects to discontinue } \\
\text { using their cochlear implant }\end{array}$ & 0.077 & Kumar et al. [54] & $0.009,0.206$ & Beta \\
\hline $\begin{array}{l}\text { Proportion of people who receive a benefit } \\
\text { from using a hearing aid }\end{array}$ & 0.50 & $\begin{array}{l}\text { Bond et al. [25] reconfirmed through expert } \\
\text { opinion }\end{array}$ & $0.061,0.939$ & Beta \\
\hline Mean lifetime of an acoustic hearing aid & 5 years & $\begin{array}{l}\text { Bond et al. [25] reconfirmed through expert } \\
\text { opinion }\end{array}$ & 1.3 years, 11 years & Gamma \\
\hline Mean time to sound processor upgrade & 106 months & Cochlear Limited Internal Database (2018) & 29 months, 232 months & Gamma \\
\hline $\begin{array}{l}\text { Proportion of unilateral candidates adopting } \\
\text { a hearing aid and are compliant }\end{array}$ & 0.50 & $\begin{array}{l}\text { Bond et al. [25] reconfirmed through expert } \\
\text { opinion }\end{array}$ & $0.061,0.939$ & Beta \\
\hline
\end{tabular}

${ }^{a}$ Failure rates were derived from a retrospective review of 235 cases of cochlear implant revisions between 1982 and 2011 within the Sydney (Australia) Cochlear Implant Centre [53]. While internal data from Cochlear Limited suggested lower failure rates are associated with Cochlear Limited implants, these may not represent the average failure rate of all manufacturer's cochlear implants available through the NHS

\section{Utilities}

A systematic literature review was undertaken to extract health state utility values relating to hearing loss, cochlear implants and hearing aids in adults aged 18 years and over. While UK studies were preferred, studies from other countries with similar health care systems were also explored. Utilities derived from persons with severe to profound sensorineural hearing loss within a randomised controlled trial were prioritised, along with studies using the HUI3, given this instrument includes hearing and speech domains [35-37].

Utility decrements from severe to profound sensorineural hearing loss were calculated by subtracting the HUI3 utility score of having no cochlear intervention derived from a UK study [5], from the Canadian HUI3 population utility norm. Due to the lack of HUI3 population utility norms for the UK, the model applied the Canadian set of population utility norms (as opposed to either the Australian or US set) given it was considered the most comprehensive and recent. This allowed the model to reduce population norm utilities over time, reflecting poorer quality of life associated with comorbidities and ageing (Table 2).

A literature review was conducted to identify utility decrements associated with short-term adverse events and long-term adverse events associated with cochlear implant surgery. There were 17 different types of adverse events associated with cochlear implants found within the literature, excluding device complications such as electrode migration. These were allocated to six categories, including infection (skin infections, otitis media), neurological complications (facial palsy, dysgeusia), pain (facial stimulation, other), tinnitus (worsening or new occurrence), vestibular complications (vertigo, dizziness), and other complications (cerebrospinal fluid leak hematoma, atlantoaxial subluxation). Only those with a prevalence of greater than one $\%$ were included in the model, which include dysgeusia (taste disturbance), vertigo, tinnitus and wound infection (Table 3). It was assumed that short-term adverse events would last for six months. They were included in the model as a weighted average of disutility using the probability of experiencing an adverse event as weights (Table 4).

\section{Costs}

Costs were calculated by multiplying the volume of resource use associated with interventions by their unit cost (Tables 5 , $6,7,8,9,10)$. Resource use was largely based on clinical expert opinion sought within the development of the clinical pathway. Hearing aid costs depended on the number of 


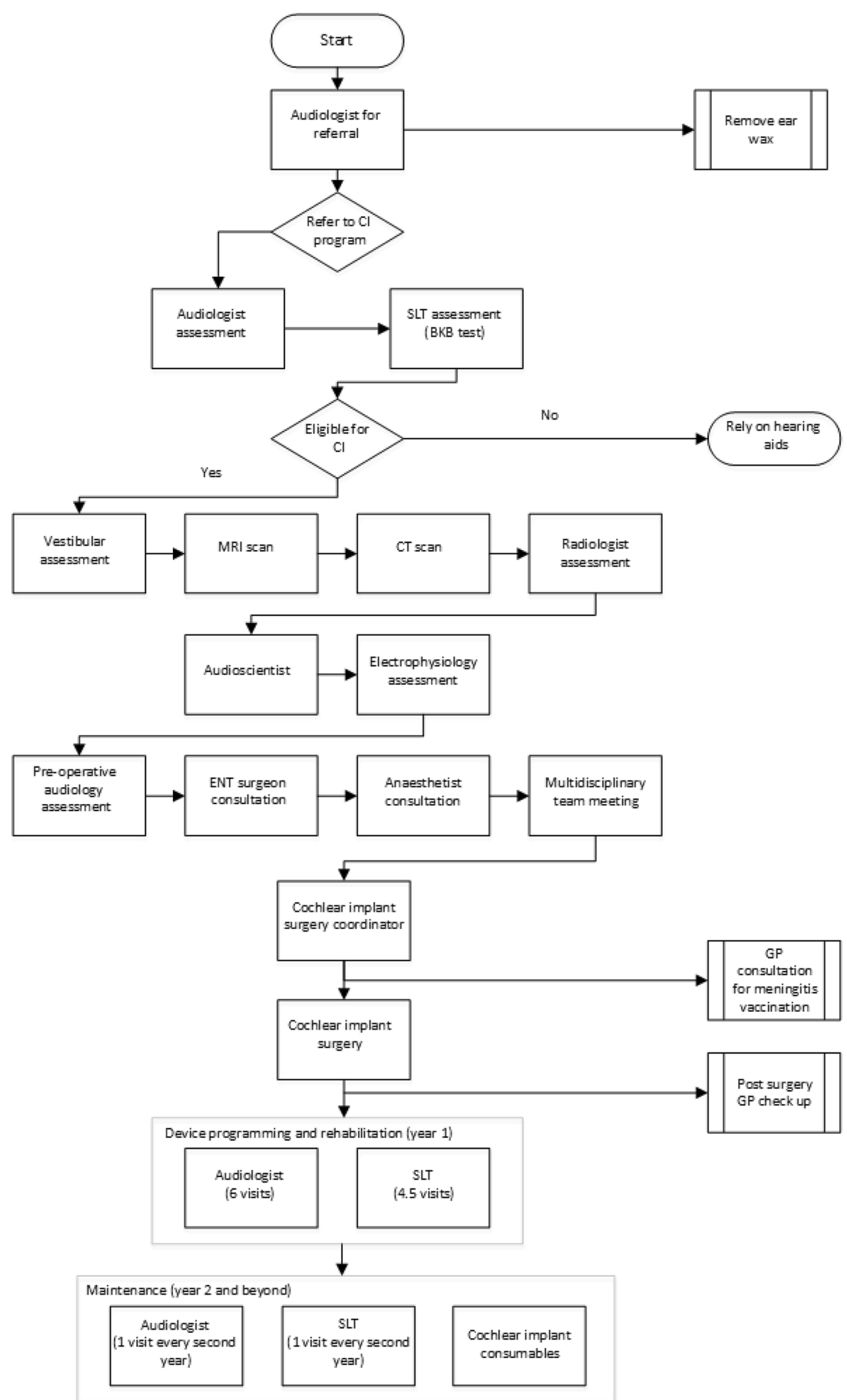

Note: Does not include resource use associated with sound processor replacement, explant and re-implant and adverse events. Cl cochlear implant; CT computed tomography; ENT ear, nose and throat; GP general practitioner; MRI magnetic resonance imaging; SLT speech and language therapist

Fig. 4 Pathway for resource use associated with a cochlear implant 
Table 2 Utility values

\begin{tabular}{lcc}
\hline Health state & Utility & Source \\
\hline Severe and profound hearing loss prior to a cochlear implant & & \\
Traditional candidates ${ }^{\mathrm{a}}$ & 0.410 & UKCISG [5] \\
Marginal hearing aid users $^{\mathrm{b}}$ & 0.494 & \\
Utility decrement from population utility norms for persons with severe and profound hearing loss \\
Traditional candidates & 0.439 & \\
Marginal hearing aid users & 0.374 & Calculated by subtracting the HUI3 utility score of having no \\
& & cochlear intervention from the Canadian HUI3 population utility \\
& & norm \\
Utility increment associated with the intervention received & & \\
Unilateral cochlear implant & 0.214 & UKCISG [5] \\
$\quad$ Traditional candidates & 0.151 & UKCISG [5] \\
$\quad$ Marginal hearing aid users & &
\end{tabular}

${ }^{a}$ Traditional candidates are those people for whom a hearing aid provided no benefit

${ }^{\mathrm{b}}$ Marginal hearing aid users are those persons for whom a hearing aid provided some benefit

Table 3 Disutility values

\begin{tabular}{|c|c|c|c|}
\hline Health state & Disutility & Duration & Source \\
\hline \multicolumn{4}{|c|}{ Short-term adverse events } \\
\hline $\begin{array}{c}\text { Dysgeusia (taste } \\
\text { disturbance) }\end{array}$ & 0.020 & 6 months & Authors assumption \\
\hline Vertigo & 0.033 & 6 months & Swan et al. [55] \\
\hline Tinnitus & 0.050 & 6 months & Happich et al. [56] \\
\hline Wound infection & 0.042 & 6 months & Prosser et al. [57] \\
\hline \multicolumn{4}{|c|}{ Long-term adverse events } \\
\hline Vertigo & 0.033 & Lifetime & Swan et al. [55] \\
\hline
\end{tabular}

hearing aids a patient was using before receiving a UCI. Persons with hearing aids that receive a UCI were assumed to no longer require a hearing aid in the ear receiving the implant and to continue wearing their contralateral hearing aid.

Unit costs were derived from clinical expert opinion, literature reviews, NHS National Schedule of Reference Costs,
NHS National Tariff: Currencies and Prices, the Personal Social Services Research Unit, and literature.

\section{Sensitivity analyses}

A sensitivity analysis of key model parameters was undertaken to assess the sensitivity of the ICERs to key model parameters. Parameters were chosen based on their expected level of uncertainty and potential influence on ICERs. Their range was dictated by the $95 \%$ confidence interval around the estimate (where available), while an arbitrary range was determined for all other parameters [38].

A probabilistic analysis using Monte Carlo simulation was also conducted, using distributions attached to each model parameter, with 10,000 samples drawn at random from these distributions to calculate a distribution of ICERs. Fixed random number seeds were used to minimise random simulation error [39]. A cost-effectiveness acceptability curve (CEAC) was produced to determine the probability

Table 4 Probability of adverse events

\begin{tabular}{|c|c|c|}
\hline Parameter & Probability & Source \\
\hline \multicolumn{3}{|l|}{ Short-term adverse events } \\
\hline Dysgeusia (taste disturbances) & 0.065 & Inverse weighted average of Hanson et al. [58], Jeppesen et al. [59], and Farinetti et al. [60] \\
\hline Vertigo & 0.194 & $\begin{array}{l}\text { Inverse weighted average of Hanson et al. [58], Jeppesen et al. [59], Farinetti et al. [60], and } \\
\text { Venail et al. [61] }\end{array}$ \\
\hline Infection & 0.015 & $\begin{array}{l}\text { Inverse weighted average of Hanson et al. [58], Jeppesen et al. [59], Stamatiou et al. [62], Farinetti } \\
\text { et al. [60], Venail et al. [61] }\end{array}$ \\
\hline Tinnitus & 0.036 & Inverse weighted average of Jeppesen et al. [59], Farinetti et al. [60] and Venail et al. [61] \\
\hline \multicolumn{3}{|l|}{ Long-term adverse events } \\
\hline Vertigo & 0.014 & Inverse weighted average of Hanson et al. [58] and Jeppesen et al. [59] \\
\hline
\end{tabular}


Table 5 Pre-implant assessment resource use and unit costs

\begin{tabular}{|c|c|c|c|c|c|c|}
\hline Resource & $\begin{array}{l}\text { No. of } \\
\text { visits }\end{array}$ & Units & Unit type & & 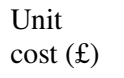 & Source \\
\hline \multicolumn{7}{|l|}{ Referral } \\
\hline Audiologist & 1 & 1 & Consultation & & 84 & NHS National Schedule of Reference Costs [30] \\
\hline Removing earwax & & 1 & Hours & & 106 & NHS National Schedule of Reference Costs [30] \\
\hline \multicolumn{7}{|l|}{ Stage 1: initial assessment } \\
\hline Audiologist & 1 & 1.5 & Hours & & 84 & NHS National Schedule of Reference Costs [30] \\
\hline SLT & 1 & 1.5 & Hours & & 96 & NHS National Schedule of Reference Costs [30] \\
\hline \multicolumn{7}{|l|}{ Stage 2: testing } \\
\hline Vestibular assessment and tests & & 1.5 & Hours & & 86 & NHS National Schedule of Reference Costs [30] \\
\hline Radiologist & 1 & 1 & Hours & & 74 & Curtis and Burns [63] \\
\hline MRI scan & & 1 & Hours & & 138 & NHS National Schedule of Reference Costs [30] \\
\hline CT scan & & 1 & Hours & & 88 & NHS National Schedule of Reference Costs [30] \\
\hline \multicolumn{7}{|l|}{ Stage 3: electrophysiology } \\
\hline Audioscientist & 1 & 1 & Hours & & 84 & NHS National Schedule of Reference Costs [30] \\
\hline Electrophysiology assessment & & 1 & Hours & & 70 & Curtis and Burns [63] \\
\hline \multicolumn{7}{|l|}{ Stage 4: medical assessment } \\
\hline Audiologist pre-operative assessment & 1 & 1.5 & Hours & & 84 & NHS National Schedule of Reference Costs [30] \\
\hline ENT surgeon consultation & 1 & 1 & Hours & & 104 & NHS National Schedule of Reference Costs [30] \\
\hline Anaesthetist consultation & 1 & 1 & Hours & & 130 & NHS National Schedule of Reference Costs [30] \\
\hline $\begin{array}{l}\text { Multidisciplinary team meeting } \\
\text { - Audiology } \\
\text { - SLT } \\
\text { - ENT specialist }\end{array}$ & 1 & 1 & Hours & & 284 & $\begin{array}{l}\text { Aggregated unit costs using NHS National } \\
\text { Schedule of Reference Costs [30] }\end{array}$ \\
\hline GP consultation for meningitis vaccination & 1 & 1 & Consultation & & 31 & Curtis and Burns [63] \\
\hline Meningitis vaccination & & 1 & Unit & & 60 & NHS Vaccine Price List \\
\hline \multicolumn{7}{|c|}{ Stage 5: pre-procedural assessment outcome discussion } \\
\hline Cochlear implant surgery coordinator & 1 & & & Hours & 44 & Curtis and Burns [63] \\
\hline
\end{tabular}

$C T$ computerized tomography; ENT ear, nose and throat; GP general practitioner; $M R I$ magnetic resonance imaging; $N H S$ national health service; $S L T$ speech and language therapist

of the ICERs being cost-effective across the assumed costeffectiveness threshold of $£ 20,000$ per QALY [38].

\section{Model validation}

Model validation was undertaken using the Assessment of the Validation Status of Health-Economic decision models (AdViISHE) tool [40]. Internal consistency was checked by ensuring probabilities lied between zero and one and probabilities following a chance node summed to one. Two additional people reviewed the mathematical logic of the model, including equations, coding and model inputs. We used null and extreme values within a sensitivity analysis to determine whether subsequent results meet apriori expectations.

The model was checked for external consistency by first comparing ICERs using inputs derived from the NICE Health Technology Assessment Report. This allowed the structure and mathematical logic of the model to be tested, while holding differences in model inputs constant. ICERs generated using model inputs derived within this study were also compared. The model was also validated by clinical experts on whether the assumptions and structure of the model were reliable and could be reasonably explained.

\section{Results}

\section{Base case results}

A UCI for someone that had previously worn a hearing aid in the ear that received the implant led to an average incremental lifetime cost increase of $£ 37,988$, and an additional 3.18 QALYs. This equates to an ICER of $£ 11,946$ per QALY gained.

A UCI for someone that had not previously worn a hearing aid in the ear that received the implant led to an average incremental lifetime cost increase of $£ 38,449$ and an additional 3.66 QALYs. This equates to an ICER of $£ 10,499$ per QALY gained (see Table 11). The improved ICER comes 


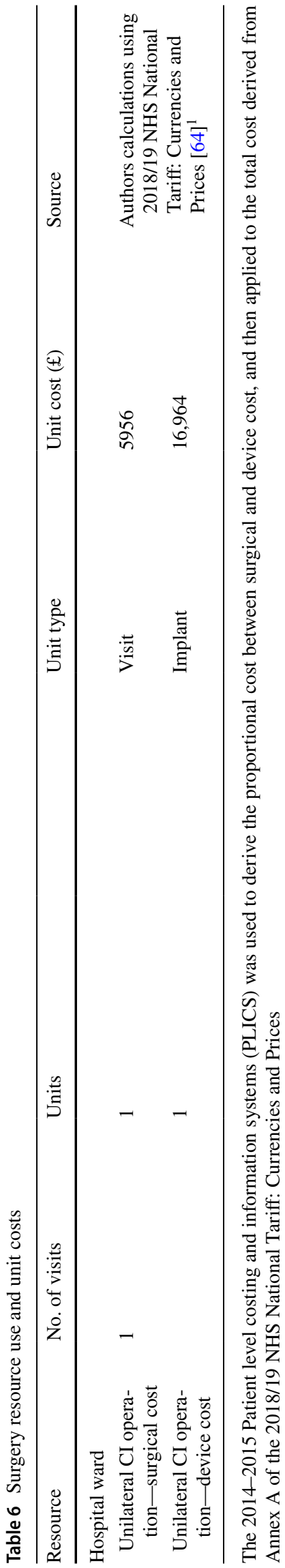

from the greater benefit from a UCI, given no benefit from a hearing aid had been received prior.

\section{Sensitivity analysis}

A probabilistic sensitivity analysis showed the ICER associated with a UCI compared to a hearing aid or no hearing aid was sensitive to the discount rate, surgery and device costs, processor upgrade cost and processor cycle time, audiologist costs after the implant, and the utility increment associated with a UCI (Fig. 5).

All simulated results for a UCI in the probabilistic sensitivity analysis (PSA) fell into the northeast quadrant of the cost-effectiveness plane, indicating that a UCI is more expensive but also more effective (Figs. 6, 7). Most simulated mean differences in costs and QALYs are below the $£ 20,000$ per QALY gained threshold, indicating a UCI compared to a hearing aid, or no hearing aid, is likely to be costeffective. CEACs show that a UCI has an $93.0 \%$ likelihood of being cost-effective when compared to a hearing aid, and a $98.7 \%$ likelihood of being cost-effective when compared to no hearing aid (Figs. 8, 9).

\section{Discussion}

Modelling results suggest a UCI for adults with severe to profound hearing loss is cost-effective when compared to a hearing aid or no hearing aid. ICERs were well below the NICE cost-effectiveness threshold and CEACs suggest the probability of UCIs being cost-effective is between 93.0\% and $98.7 \%$. These results align with the NICE Health Technology Assessment Report conducted in 2009 [25]. It found the ICER for a UCI compared to no UCI was $£ 14,163$ per QALY for adults aged 50 years, with a $100 \%$ probability of being cost-effective at a $£ 20,000$ per QALY threshold.

Differences in the ICERs reported between the two studies may relate to changes in clinical pathways, resource use and unit costs. Our incremental lifetime costs were up to $£ 4493$ more (for someone previously not wearing a hearing aid) compared to the estimate in the NICE Health Technology Assessment Report. While pre-surgical costs and post-surgical costs were lower within our study, there were greater costs associated with cochlear implant surgery, device costs and hearing aids. The largest difference was in surgery and device costs, with our study estimating an additional $£ 3142$ and $£ 2352$, respectively.

Our study developed a likely pre-surgical and post-procedural pathway currently operating in the UK, and applied unit costs derived from the NHS to expected resource use, including surgery and device costs. The UK Health 
Table 7 Hearing aid resource use and unit costs

\begin{tabular}{|c|c|c|c|c|c|}
\hline Resource & No. of visits & Units & Unit type & Unit cost $(£)$ & Source \\
\hline One hearing aid & 1 & 1 & Unit & 166 & $\begin{array}{l}\text { NHS National } \\
\text { Schedule of } \\
\text { Reference } \\
\text { Costs [30] }\end{array}$ \\
\hline Pair of hearing aids & 1 & 1 & Unit & 332 & $\begin{array}{l}\text { NHS National } \\
\text { Schedule of } \\
\text { Reference } \\
\text { Costs [30] }\end{array}$ \\
\hline
\end{tabular}

Table 8 Device programming and rehabilitation resource use and unit costs

\begin{tabular}{llllll}
\hline Resource & No. of visits & Units & Unit type & Unit cost (£) & Source \\
\hline $\begin{array}{l}\text { Initial care-Year 1 } \\
\quad \text { GP medical check }\end{array}$ & 1 & 1 & Consultation & 31 & Curtis and Burns [63] \\
$\begin{array}{l}\text { CI programming } \\
\quad \text { Audiologist }\end{array}$ & 6 & & & & \\
$\begin{array}{l}\text { Familiarisation with using the device and aural training } \\
\text { SLT }\end{array}$ & 4.5 & 1.5 & Hours & 84 & NHS National Schedule of Reference Costs [30] \\
$\begin{array}{l}\text { Follow-up care-Year 2 and beyond } \\
\quad \begin{array}{l}\text { Audiologist (tuning visit) } \\
\text { SLT (tuning visit) }\end{array}\end{array}$ & 1 & Hours & 96 & NHS National Schedule of Reference Costs [30] \\
$\begin{array}{l}\text { Annual equipment maintenance (batter- } \\
\text { ies, cables, coils and sound processor }\end{array}$ & 1 & 1 & Hours & 84 & NHS National Schedule of Reference Costs [30] \\
$\quad$ repairs) & 1 & Hours & 96 & NHS National Schedule of Reference Costs [30] \\
CI annual administration & 1 & Units & 328 & NHS National Schedule of Reference Costs [30] \\
\hline
\end{tabular}

$C I$ cochlear implant; $G P$ general practitioner; $S L T$ speech and language therapist

Technology Report study estimated resource use and costs from a UK Cochlear Implant Study Group report conducted in 2004 [41]. That study relied on estimated cost information sourced from five NHS hospitals up to eight years before 1999, along with clinical and hospital accountant consultations.

Differences in methods and assumptions have also impacted results. This study estimated a patient is around three years older when they receive a cochlear implant compared to the NICE Health Technology Assessment Report, and there were differences in the number and types of adverse events a patient could experience. This study undertook a comprehensive literature review on adverse events to populate the model, while the NICE Health Technology Assessment Report relied on two studies to populate their model. The NICE Health Technology Assessment Report assumed reduced costs for internal device failure, repairs and replacement within a warranty period, which this study did not.

Differing Markov model structures may have also impacted results. The NICE Health Technology Assessment Report allowed voluntary non-use of the cochlear implant, allowing UCI recipients to revert to their original hearing support. Our model allowed UCI recipients to revert to either their hearing aid or no hearing aid, but only if the device failed internally. Furthermore, our model produced two separate ICERs, one for adults with some benefit from hearing aids and another for adults with no benefit from hearing aids prior to receiving a UCI. The NICE Health Technology Assessment Report reported one ICER for all adults.

This study found ICERs were sensitive to the proportion of people eligible for a UCI. This has implications for improving the awareness of access to UCIs after the change in NICE criteria. An influx of people seeking a UCI may increase the ICER if they are deemed ineligible through initial testing. Increased use of audiologists and speech and language therapists would increase costs without a commensurate increase in health outcomes. Improving the quality of referrals from referring clinics through better data collection and education, and carefully managing expectations regarding access to UCIs, is therefore warranted. 
Table 9 Sound processor replacement / upgrade, explant and re-implant resource use and unit costs

\begin{tabular}{|c|c|c|c|c|c|}
\hline Resource & No. of visits & Units & Unit type & Unit cost $(£)$ & Source \\
\hline \multicolumn{6}{|l|}{ Sound processor replacement/upgrade } \\
\hline External component & 1 & 1 & Unit & 5000 & Cochlear Limited \\
\hline Audiologist (tuning visit) & 1 & 1.5 & Hours & 84 & NHS National Schedule of Reference Costs [30] \\
\hline SLT (tuning visit) & 1 & 1.5 & Hours & 96 & NHS National Schedule of Reference Costs [30] \\
\hline \multicolumn{6}{|l|}{ Explant } \\
\hline Audiologist (assessment) & 1 & 1.5 & Hours & 84 & NHS National Schedule of Reference Costs [30] \\
\hline Explant & & 1 & Visit & 4253 & NHS National Schedule of Reference Costs [30] \\
\hline \multicolumn{6}{|l|}{ Re-implant } \\
\hline Audiologist pre-operative assessment & 1 & 1.5 & Hours & 84 & NHS National Schedule of Reference Costs [30] \\
\hline ENT surgeon consultation & 1 & 1 & Hours & 104 & NHS National Schedule of Reference Costs [30] \\
\hline Anaesthetist consultation & 1 & 1 & Hours & 130 & NHS National Schedule of Reference Costs [30] \\
\hline $\begin{array}{l}\text { Multidisciplinary team meeting } \\
\text { - Audiology } \\
\text { - SLT } \\
\text { - ENT }\end{array}$ & 1 & 1 & Hours & 284 & $\begin{array}{l}\text { Aggregated unit costs using NHS National } \\
\text { Schedule of Reference Costs [30] }\end{array}$ \\
\hline Cochlear implant surgery coordinator & 1 & 1 & Hours & 44 & Curtis and Burns [63] \\
\hline Unilateral CI operation-surgical cost & 1 & 1 & Visit & 5956 & $\begin{array}{l}\text { Authors calculations using NHS National } \\
\text { Schedule of Reference Costs }[30]^{\mathrm{a}}\end{array}$ \\
\hline GP medical check & 1 & 1 & Consultation & 31 & Curtis and Burns [63] \\
\hline
\end{tabular}

$C I$ cochlear implant; $E N T$ ear, nose and throat; GP general practitioner; SLT speech and language therapist

${ }^{a}$ The 2014-2015 Patient level costing and information systems (PLICS) was used to derive the proportional cost between surgical and device cost, and then applied to the total cost derived from Annex A of the National tariff payment system 2017-2018 and 2018-2019

Table 10 Resource use and unit costs associated with short-term and long-term adverse events

\begin{tabular}{|c|c|c|c|c|c|}
\hline Parameter & No. of visits & Units & Unit type & Unit cost $(£)$ & Source \\
\hline \multicolumn{6}{|c|}{ Short-term adverse events } \\
\hline \multicolumn{6}{|c|}{ Taste disturbances, Vertigo, Tinnitus } \\
\hline GP visit & 1 & 1 & Consultation & 31 & Curtis and Burns [63] \\
\hline \multicolumn{6}{|l|}{ Infection } \\
\hline GP visit & 1 & 1 & Consultation & 31 & Curtis and Burns [63] \\
\hline Antibiotics & & 1 & Course & 10 & $\begin{array}{l}\text { Based on NHS prescription charge [65] and } \\
\text { Amoxicillin (Cap } 500 \mathrm{mg} \text { ) [66] }\end{array}$ \\
\hline \multicolumn{6}{|c|}{ Long-term adverse events } \\
\hline \multicolumn{6}{|l|}{ Vertigo } \\
\hline GP visit & 1 & 1 & Consultation & 31 & NHS National Schedule of Reference Costs [30] \\
\hline
\end{tabular}

Short-term adverse events are defined as those lasting six months or less. Long-term adverse events are defined as those lasting a lifetime

\section{Limitations}

While a UCI was estimated to be cost-effective, QALYs may have been underestimated given the most reliable utility estimates were taken from a study completed two decades ago [5]. The introduction of digital processors alongside the use of dual microphones in 2004 represented a major leap forward in cochlear implant technology, helping recipients with directional hearing. Cochlear implant recipients now experience improved hearing in background noise due to the introduction of technological improvements such as input (pre-)processing of the sound signal $[42,43]$. The NICE has recommended future research focus on measuring the benefits of bilateral cochlear implants compared to UCIs for adults and children.

Our model represents a simplification of the complex interaction between hearing loss and quality of life. Cost savings were not included with reduced familial support, such as avoiding the need to learn sign language or the potential increase in QALYs for others from the avoidance of stress associated with hearing loss of a family member. 
Table 11 Cost-effectiveness results

\begin{tabular}{|c|c|c|c|}
\hline \multirow[t]{2}{*}{ Strategy } & \multicolumn{2}{|c|}{ Reference case } & \multirow[b]{2}{*}{$\begin{array}{l}\text { ICER ( } £ \\
\text { per QALY) }\end{array}$} \\
\hline & Cost $(\mathfrak{f})$ & QALY & \\
\hline \multicolumn{4}{|l|}{ Deterministic results } \\
\hline \multicolumn{4}{|l|}{ Hearing aids ${ }^{\mathrm{a}}$} \\
\hline Hearing aid & 464 & 6.78 & \\
\hline Unilateral cochlear implant & 38,449 & 9.96 & \\
\hline Difference & 37,985 & 3.18 & 11,946 \\
\hline \multicolumn{4}{|l|}{ No hearing aids ${ }^{\mathrm{b}}$} \\
\hline No hearing aid & 0 & 6.26 & \\
\hline Unilateral cochlear implant & 38,449 & 9.92 & \\
\hline Difference & 38,449 & 3.66 & 10,499 \\
\hline \multicolumn{4}{|l|}{ Probabilistic results $^{\mathrm{c}}$} \\
\hline \multicolumn{4}{|l|}{ Hearing aids } \\
\hline Mean difference & 38,465 & 3.18 & 12,390 \\
\hline Confidence interval (2.5\%) & 20,547 & 3.46 & 5,943 \\
\hline Confidence interval (97.5\%) & 62,233 & 2.68 & 23,261 \\
\hline \multicolumn{4}{|l|}{ No hearing aids } \\
\hline Mean difference & 38,807 & 3.66 & 10,634 \\
\hline Confidence interval (2.5\%) & 20,307 & 3.63 & 5,594 \\
\hline Confidence interval (97.5\%) & 69,113 & 3.64 & 19,013 \\
\hline
\end{tabular}

ICER incremental cost-effectiveness ratio; $Q A L Y$ quality adjusted life years

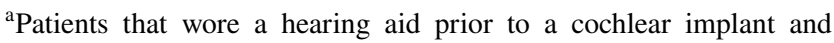
received some benefit (score of $1 \%$ to $50 \%$ on a BKB test)

${ }^{b}$ Patients that did not wear a hearing aid prior to a cochlear implant because they did not receive a benefit (score of zero on a BKB test)

${ }^{\mathrm{c}}$ Derived from Monte Carlo simulation using 10,000 iterations
Despite research showing severe to profound hearing loss reduces productivity [44-49], no studies were found that measured the potential increase in productivity from a cochlear implant. One study included potential changes in productivity within their economic evaluation, although this related only to the expected productivity loss associated with having to take time off work for audiology assessments and surgery [34].

The impact of hearing loss on the severity and onset of dementia were also not considered. While several studies have evaluated the impact of hearing aids on cognitive function [50], no studies have evaluated the impacts of improved hearing from cochlear implants on dementia. One study conducted in France suggests cochlear implants may improve cognitive function [12]. It recruited 94 patients aged between 65 and 85 years old and provided them with a UCI and two sessions with a speech therapist each week for six months or more. Around $80 \%$ of the patients with the poorest Mini-Mental State Examination scores before implantation improved their cognitive function one year after implantation. However, the study could not separate the effects of speech perception improvement from the cochlear implant and the cognitive training that was also provided to patients [66].

If empirically validated, a reduction in dementia risk from cochlear implants would represent a significant benefit. One study has estimated that even delaying the onset of dementia by one year would decrease the prevalence of dementia around the world by $10 \%$ in 2050 [51]. Dementia currently costs over 1 trillion U.S. dollars per year and is expected to grow as the population ages [52].

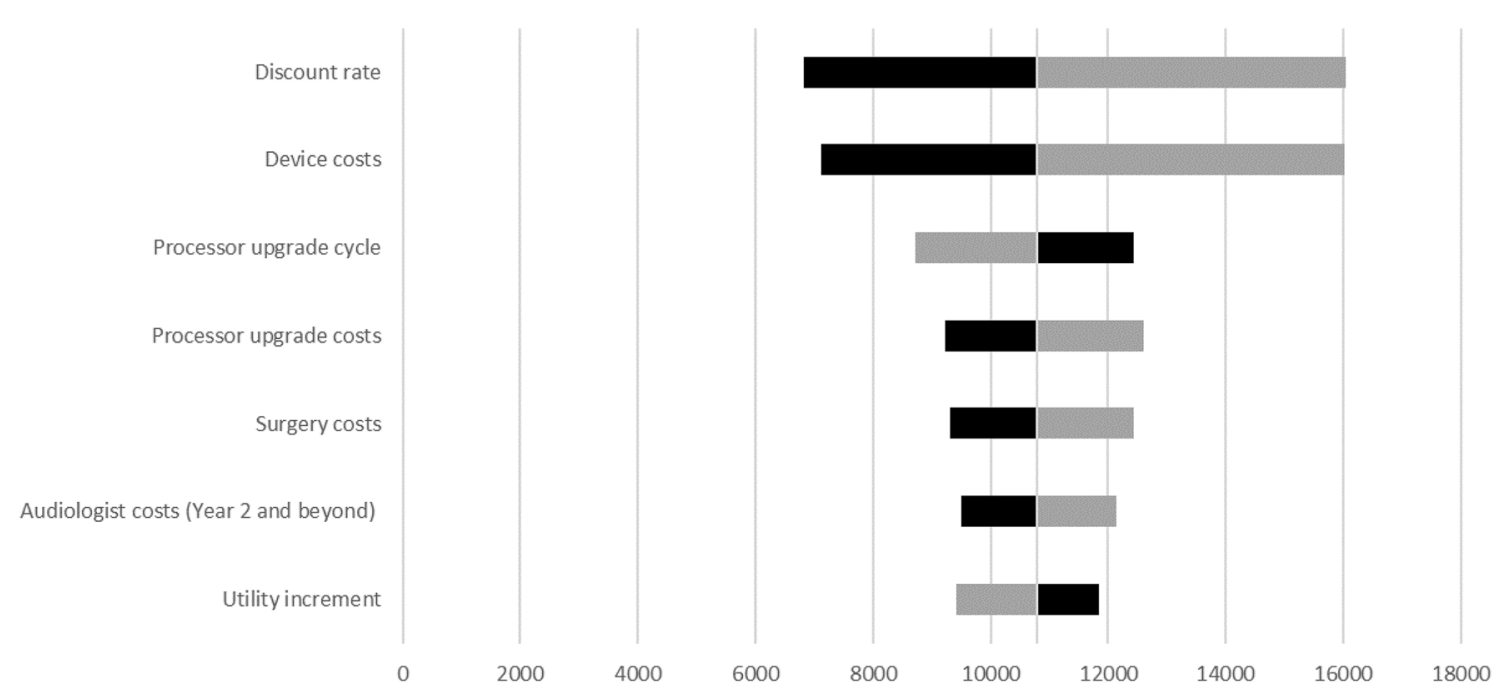

Note: Sensitivity of the ICER associated with unilateral cochlear implants for people that had previously worn a hearing aid was almost identical to unilateral cochlear implants for people that had not previously worn a hearing aid so the former has not been presented here

Fig. 5 Sensitivity of the ICER for a unilateral cochlear implant compared to no hearing aids 
Fig. 6 Mean differences in costs and QALYs for a unilateral cochlear implant vs a hearing aid

Fig. 7 Mean differences in costs and QALYs for a unilateral cochlear implant vs no hearing aid

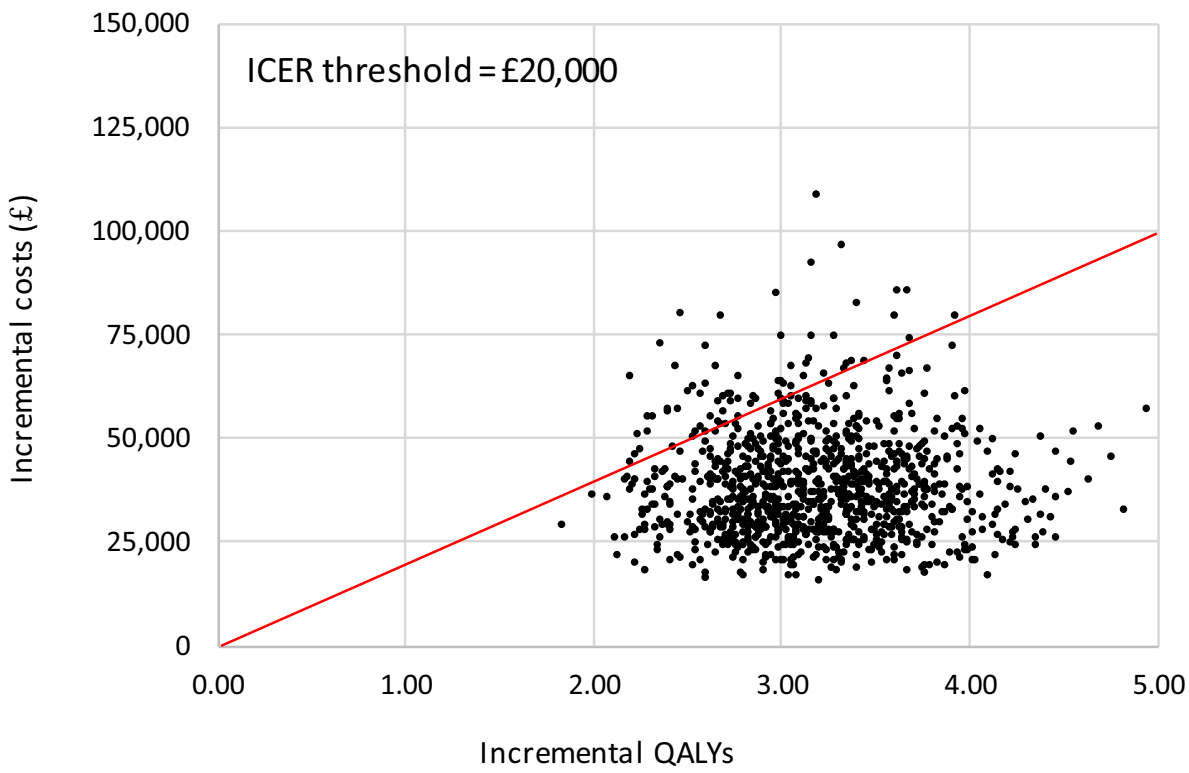

Note: 1 . Patients that wore a hearing aid prior to a cochlear implant and received some benefit (score of $1 \%$ to $50 \%$ on a BKB test). 2. Derived from Monte Carlo simulation using 10,000 iterations

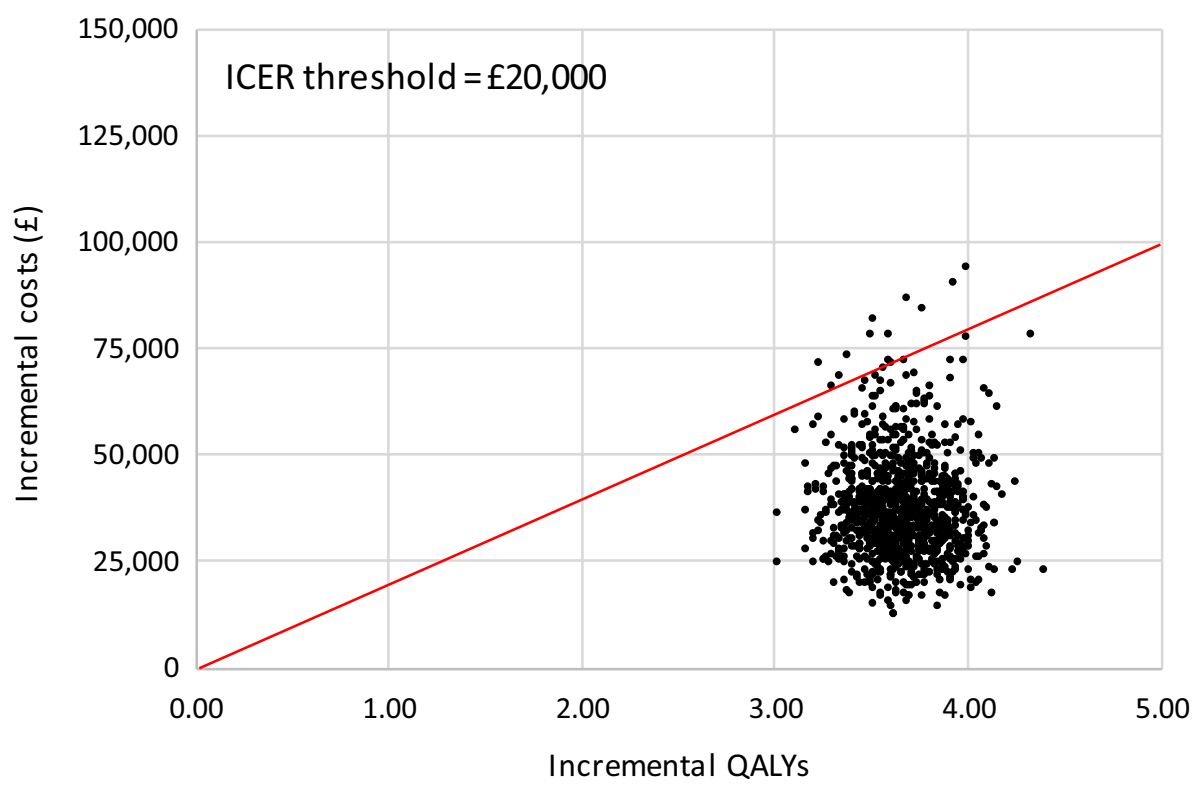

Note: 1. Patients that did not wear a hearing aid prior to a cochlear implant because they did not receive a benefit (score of zero on a BKB test). 2. Derived from Monte Carlo simulation using 10,000 iterations 
Fig. 8 Cost-effectiveness acceptability curve for a unilateral cochlear implant vs a hearing aid

Fig. 9 Cost-effectiveness acceptability curve for a unilateral cochlear implant vs no hearing aid

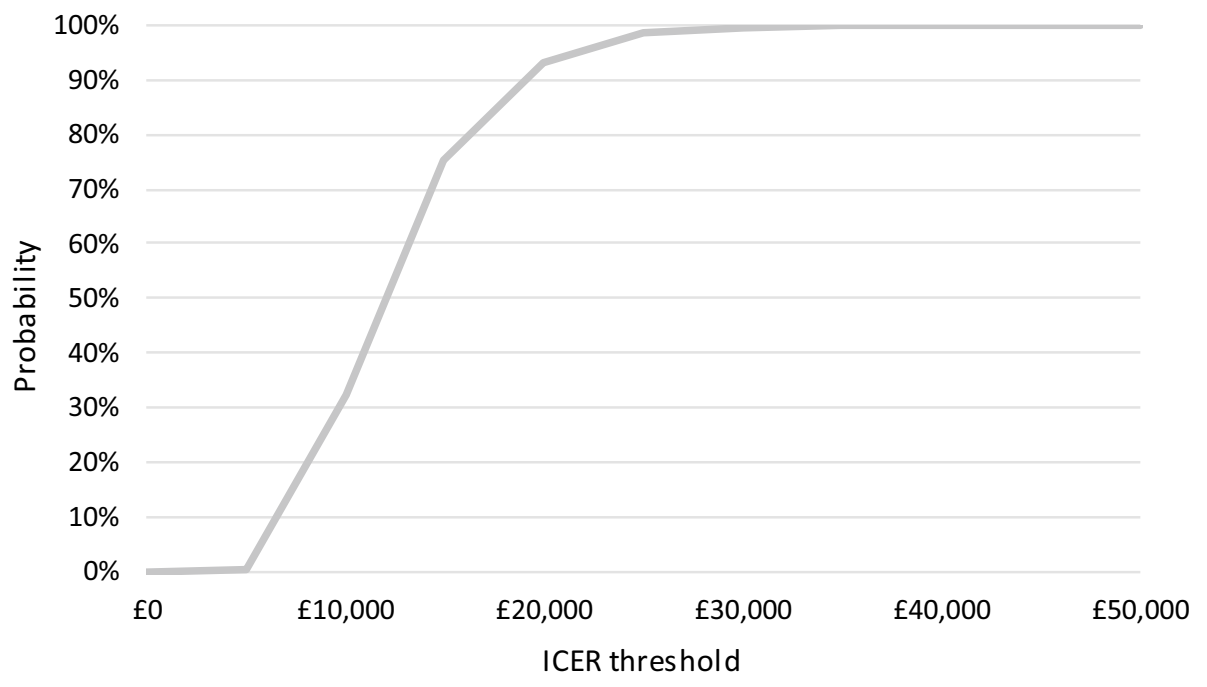

Note: 1. Patients that wore a hearing aid prior to a cochlear implant and received some benefit (score of $1 \%$ to $50 \%$ on a BKB test). 2. Derived from Monte Carlo simulation using 10,000 iterations

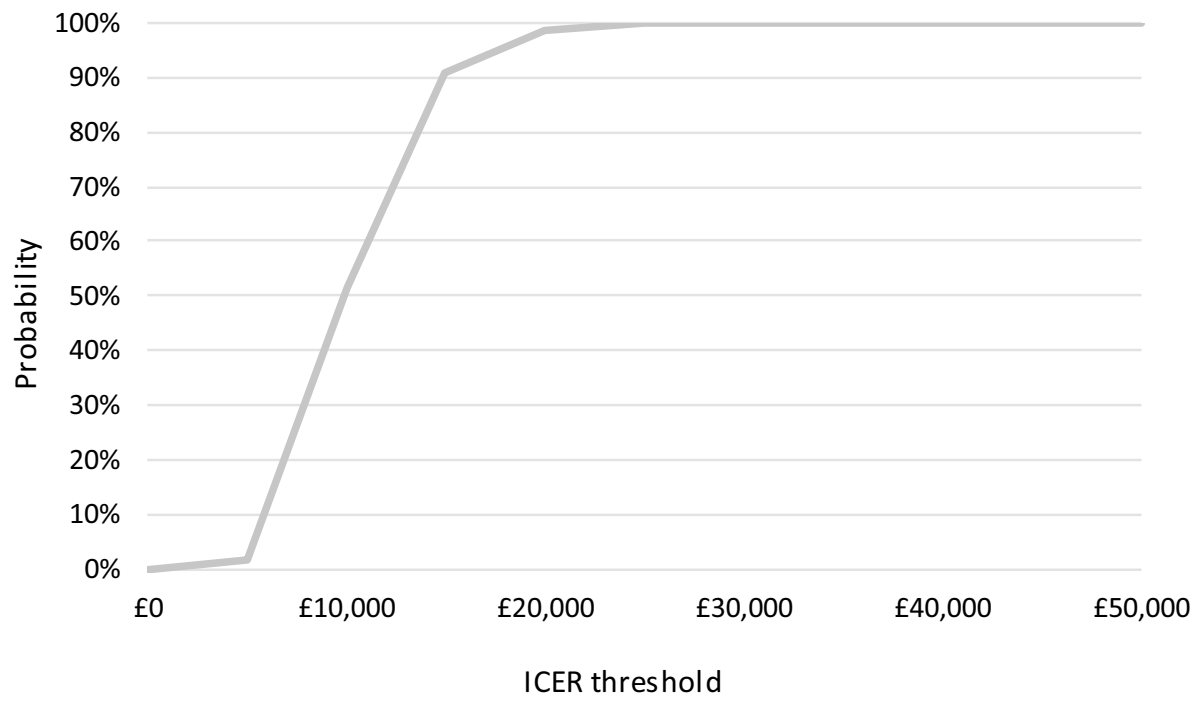

Note: 1 . Patients that did not wear a hearing aid prior to a cochlear implant because they did not receive a benefit (score of zero on a BKB test). 2. Derived from Monte Carlo simulation using 10,000 iterations 


\section{Conclusion}

This study demonstrates that UCIs remain cost-effective since the UK Health Technology Report associated with the original NICE guidance was completed in 2009, despite changes to clinical practice and increased healthcare unit costs. Investment in improved awareness among clinicians and those with severe to profound hearing loss on access to, and potential benefits from, UCIs would further enhance access and improve quality of life and overall social welfare.

Acknowledgements This research was funded by Cochlear Limited. We would like to thank Fernando Gonzalo (Cochlear Limited) for his review of draft documents. We would also like to thank Leigh Miller (formally of Cochlear Limited), Tracey Twomey (Nottingham Auditory Implant Programme), and Associate Professor Padraig Kitterick (University of Nottingham) for useful comments in developing the clinical pathway towards receiving a unilateral cochlear implant.

Open Access This article is licensed under a Creative Commons Attribution 4.0 International License, which permits use, sharing, adaptation, distribution and reproduction in any medium or format, as long as you give appropriate credit to the original author(s) and the source, provide a link to the Creative Commons licence, and indicate if changes were made. The images or other third party material in this article are included in the article's Creative Commons licence, unless indicated otherwise in a credit line to the material. If material is not included in the article's Creative Commons licence and your intended use is not permitted by statutory regulation or exceeds the permitted use, you will need to obtain permission directly from the copyright holder. To view a copy of this licence, visit http://creativecommons.org/licenses/by/4.0/.

\section{References}

1. Action on Hearing Loss: Hearing Matters. Action on Hearing Loss, London (2017)

2. Kessler, D., Osberger, M., Boyle, P.: CLARION patient performance: an update on the adult and children's clinical trials. Scand. Audiol. 26, 45-49 (1997)

3. Mawman, D., et al.: Trends and outcomes in the Manchester adult cochlear implant series. Clin. Otolaryngol. Allied Sci. 29(4), 331339 (2004)

4. Parkinson, A., et al.: The nucleus 24 contour cochlear implant system: adult clinical trial results. Ear Hear. 23(1), 41S-48S (2002)

5. UK Cochlear Implant Study Group: Criteria of candidacy for unilateral cochlear implantation in postlingually deafened adults II: cost-effectiveness analysis. Ear Hear. 25(4), 336-360 (2004)

6. Ching, T.Y., Incerti, P., Hill, M.: Binaural benefits for adults who use hearing aids and cochlear implants in opposite ears. Ear Hear. 25(1), 9-21 (2004)

7. Hamzavi, J., et al.: Hearing performance in noise of cochlear implant patients versus severely-profoundly hearing-impaired patients with hearing aids. Audiology 40(1), 26-31 (2001)

8. Bassim, M., et al.: MED-EL Combi40+ cochlear implantation in adults. Laryngoscope 115(9), 1568-1573 (2005)

9. Kraaijenga, V.J., et al.: Factors that influence outcomes in cochlear implantation in adults, based on patient-related characteristics-a retrospective study. Clin. Otolaryngol. 41(5), 585-592 (2016)
10. Hilly, O., et al.: Cochlear implantation in elderly patients: stability of outcome over time. J. Laryngol. Otol. 130(8), 706-711 (2016)

11. Lenarz, T., et al.: Patient-related benefits for adults with cochlear implantation: a multicultural longitudinal observational study. Audiol. Neurootol. 22(2), 61 (2017)

12. Mosnier, I., et al.: Improvement of cognitive function after cochlear implantation in elderly patients. JAMA Otolaryngol. Head Neck Surg. 141(5), 442-450 (2015)

13. Choi, J.S., et al.: Association of using hearing aids or cochlear implants with changes in depressive symptoms in older adults. JAMA Otolaryngol. Head Neck Surg. 142(7), 652-657 (2016)

14. Arnoldner, C., et al.: Quality of life in cochlear implantees: comparing utility values obtained through the Medical Outcome Study Short-Form Survey-6D and the Health Utility Index Mark 3. Laryngoscope 124(11), 2586-2590 (2014)

15. Contrera, K.J., et al.: Quality of life after intervention with a cochlear implant or hearing aid. Laryngoscope 126(9), 2110 2115 (2016)

16. Damen, G.W., et al.: Cochlear implantation and quality of life in postlingually deaf adults: long-term follow-up. Otolaryngol. Head Neck Surg. 136(4), 597-604 (2007)

17. Sanchez-Cuadrado, I., et al.: Is there an age limit for cochlear implantation? Ann. Otol. Rhinol. Laryngol. 122(4), 222-228 (2013)

18. Vermeire, P.L., et al.: Quality-of-life benefit from cochlear implantation in the elderly. Otol. Neurotol. 26(2), 188-195 (2005)

19. Raine, C., et al.: Access to cochlear implants: time to reflect. Cochlear Implants Int. 17(Suppl 1), 42-46 (2016)

20. Vickers, D., De Raeve, L., Graham, J.: International survey of cochlear implant candidacy. Cochlear Implants Int. 17(Suppl 1), 36-41 (2016)

21. Vickers, D.A., et al.: Preliminary assessment of the feasibility of using $\mathrm{AB}$ words to assess candidacy in adults. Cochlear Implants Int. 17(Suppl 1), 17-21 (2016)

22. National Institute for Health and Care Excellence (NICE), Cochlear implants for children and adults with severe to profound deafness. Technology appraisal guidance [TA166]. National Institute for Health and Care Excellence (NICE), London (2009)

23. National Institute for Health and Care Excellence (NICE), Final appraisal document. Cochlear implants for children and adults with severe to profound deafness (part review of TA166). National Institute for Health and Care Excellence (NICE), London (2019)

24. National Institute for Health and Care Excellence. 890 more children and adults eligible for cochlear implants on the NHS each year.Available from: https://www.nice.org.uk/news/article/hundr eds-more-children-and-adults-eligible-for-cochlear-implants-onthe-nhs (2020)

25. Bond, M., et al.: The effectiveness and cost-effectiveness of cochlear implants for severe to profound deafness in children and adults: a systematic review and economic model. Health Technol. Assess. (Winchester, Engl.) 13(44), 1-330 (2009)

26. National Institute for Health and Care Excellence, Cochlear implants for children and adults with severe to profound deafness. Technology appraisal guidance [TA566]. National Institute for Health and Care Excellence, London (2019)

27. Curtin, L., Burns, A.: Unit costs of health and social care 2020. PSSRU University of Kent. ISBN 978-1-911353-12-6 (2020)

28. Curtis, L.: Unit costs of health and social care 2014. PSSRU University of Kent. ISBN 978-1-902671-89-5 (2014)

29. Claxton, K., et al.: Methods for the estimation of the National Institute for Health and Care Excellence cost-effectiveness threshold. Health Technol. Assess. 19(14), 1-503 (2015) 
30. National Health Service. National schedule of reference costs year: 2017-18 (2018)

31. Hainarosie, M., Zainea, V., Hainarosie, R.: The evolution of cochlear implant technology and its clinical relevance. J Med Life 7(2), $1-4$ (2014)

32. National Institute for Health and Care Excellence: Guide to the methods of technology appraisal. National Institute for Health and Care Excellence, London (2013)

33. Sanders, G.D., et al.: Recommendations for conduct, methodological practices, and reporting of cost-effectiveness analyses: second panel on cost-effectiveness in health and medicine. JAMA 316(10), 1093-1103 (2016)

34. Health Quality Ontario. Bilateral cochlear implantation: a health technology assessment. Ont. HealthTechnol. Assess. Ser. [Internet]. 18(6):1-139 (2018)]. Available from https://www.hqontario. $\mathrm{ca} /$ Portals/0/documents/evidence/reports/hta-bilateral-cochlearimplantation.pdf

35. Klop, W.M., et al.: Clinical relevance of quality of life outcome in cochlear implantation in postlingually deafened adults. Otol. Neurotol. 29(5), 615-621 (2008)

36. Ramakers, G.G., et al.: Agreement between health utility instruments in cochlear implantation. Clin. Otolaryngol. 41(6), 737-743 (2016)

37. Grutters, J.P., et al.: Choosing between measures: comparison of EQ-5D, HUI2 and HUI3 in persons with hearing complaints. Qual. Life Res. 16(8), 1439-1449 (2007)

38. Briggs, A.G.R., Blackhouse, G., et al.: Probabilistic analysis of cost-effectiveness models: choosing between treatment strategies for gastro-esophogeal reflux disease. McMaster University Centre for Health Economics and Policy Analysis Research Working Paper, Canada (2001)

39. Philips, Z., et al.: Review of guidelines for good practice in decision-analytic modelling in health technology assessment. Health Technol. Assess. 8(36), 1-158 (2004)

40. Vemer, P., et al.: AdViSHE: a validation-assessment tool of health-economic models for decision makers and model users. Pharmacoeconomics 34(4), 349-361 (2016)

41. UK Cochlear Implant Study Group: Criteria of candidacy for unilateral cochlear implantation in postlingually deafened adults I: theory and measures of effectiveness. Ear Hear 25(4), 310 335 (2004)

42. Lamb, B., Archbold, S.: Adult cochlear implantation: evidence and experience. Nottingham (2013)

43. Wolfe, C.J., et al.: Benefit of a commercially available cochlear implant processor with dual-microphone beamforming: a multicenter study. Otol. Neurotol. 33(4), 553-560 (2012)

44. Emmett, S.D., Francis, H.W.: The socioeconomic impact of hearing loss in US adults. Otol. Neurotol. 36(3), 545-550 (2015)

45. Jung, D., Bhattacharyya, N.: Association of hearing loss with decreased employment and income among adults in the United States. Ann. Otol. Rhinol. Laryngol. 121(12), 771-775 (2012)

46. Mohr, P.E., et al.: The societal costs of severe to profound hearing loss in the United States. Int. J. Technol. Assess Health Care 16(4), 1120-1135 (2000)

47. Kramer, S.E., Kapteyn, T.S., Houtgast, T.: Occupational performance: comparing normally-hearing and hearing-impaired employees using the Amsterdam Checklist for Hearing and Work. Int. J. Audiol. 45(9), 503-512 (2006)

48. Helvik, A.S., Krokstad, S., Tambs, K.: Hearing loss and risk of early retirement. The HUNT study. Eur. J. Public Health 23(4), 617-622 (2013)

49. Hogan, A., et al.: Hearing loss and paid employment: Australian population survey findings. Int. J. Audiol. 48(3), 117-122 (2009)

50. Dawes, P., et al.: Hearing loss and cognition: the role of hearing AIDS, social isolation and depression. PLoS ONE 10(3), e0119616 (2015)

51. Peracino, A.: Hearing loss and dementia in the aging population. Audiol. Neurootol. 19(Suppl 1), 6-9 (2014)

52. OECD: Care Needed: Improving the Lives of People with Dementia. OECD Publishing, Paris (2018)

53. Wang, J.T., et al.: Rates of revision and device failure in cochlear implant surgery: a 30-year experience. Laryngoscope 124(10), 2393-2399 (2014)

54. Kumar, R.S., et al.: Cochlear implantation in early deafened, late implanted adults: do they benefit? Cochlear Implants Int. 17(Suppl 1), 22-25 (2016)

55. Swan, I.R., Guy, F.H., Akeroyd, M.A.: Health-related quality of life before and after management in adults referred to otolaryngology: a prospective national study. Clin. Otolaryngol. 37(1), 35-43 (2012)

56. Happich, M., Moock, J., Von Lengerke, T.: Health state valuation methods and reference points: the case of tinnitus. Value Health 12(1), 88-95 (2009)

57. Prosser, L.A., et al.: Preferences and willingness to pay for health states prevented by pneumococcal conjugate vaccine. Pediatrics 113(2), 283-290 (2004)

58. Hansen, S., et al.: Unexpected findings and surgical complications in 505 consecutive cochlear implantations: a proposal for reporting consensus. Acta Otolaryngol. 130(5), 540-549 (2010)

59. Jeppesen, J., Faber, C.E.: Surgical complications following cochlear implantation in adults based on a proposed reporting consensus. Acta Otolaryngol. 133(10), 1012-1021 (2013)

60. Farinetti, A., et al.: Cochlear implant complications in 403 patients: comparative study of adults and children and review of the literature. Eur. Ann. Otorhinolaryngol. Head Neck Dis. 131(3), 177-182 (2014)

61. Venail, F., et al.: Reliability and complications of 500 consecutive cochlear implantations. Arch. Otolaryngol. Head Neck Surg. 134(12), 1276-1281 (2008)

62. Stamatiou, G.A., Kyrodimos, E., Sismanis, A.: Complications of cochlear implantation in adults. Ann. Otol. Rhinol. Laryngol. 120(7), 428-432 (2011)

63. Curtis, L., Burns, A.: Unit Costs of Health and Social Care 2018. PSSRU University of Kent, Kent (2018)

64. National Health Service: $2017 / 18$ and 2018/19 National Tariff Payment System. National Health Service, London (2018)

65. Dunn, P.: NHS prescription charges from April 2017. Department of Health and Social Care, London (2017)

66. NHS Digital, Prescription Cost Analysis: England 2017. UK Government Statistical Service, London (2017)

Publisher's Note Springer Nature remains neutral with regard to jurisdictional claims in published maps and institutional affiliations. 